\title{
Percepção de homens idosos sobre saúde e os serviços primários de saúde
}

\author{
Perception of elderly men about health and primary health care

\section{Percepción de los hombres ancianos sobre salud y atención primaria de salud}

Camila Polisello. Universidade de São Paulo (USP). Ribeirão Preto, SP, Brasil. mipolisello@yahoo.com.br (Autora correspondente)

Cassiana Morais de Oliveira. Universidade de São Paulo (USP). Ribeirão Preto, SP, Brasil. cassianamoraes@gmail.com

Mariana Pavan. Universidade Estadual Paulista Júlio de Mesquita Filho (UNESP). Botucatu, SP, Brasil. mpavan.fmb@gmail.com

Ricardo Gorayeb. Universidade de São Paulo (USP). Ribeirão Preto, SP, Brasil. rgorayeb@fmrp.usp.br

\section{Resumo}

Objetivo: compreender a percepção de homens idosos acerca dos temas: "Saúde", "Unidade de Saúde da Família" (USF) e "Grupos em Saúde". Métodos: estudo exploratório-descritivo, de abordagem qualitativa, com amostra de conveniência. Para selecionar os participantes, utilizou-se uma lista elaborada pela equipe com os nomes dos homens idosos da área de cobertura da USF que utilizavam os serviços de saúde oferecidos pela unidade. Para a coleta de dados realizou-se entrevista semi-estruturada e os dados foram analisados de acordo com a Análise de Conteúdo Temática. Resultados: participaram desse estudo 11 homens idosos. Os entrevistados possuem um conceito ampliado de saúde, abordando aspectos biopsicossociais em suas descrições. Eles apresentaram um bom vínculo com a USF, frequentando-a para consultas e participação em grupos de prevenção e promoção. Os participantes referiram não se engajarem em tantas atividades preventivas quanto as mulheres. Avaliam os Grupos em Saúde como benéficos, com repercussões positivas para a saúde e para a vida. Alguns, no entanto, carregam modelos de grupos de outros contextos, principalmente do mundo do trabalho, os quais não coincidem com os modelos de Grupo em Saúde. Conclusão: os participantes, por serem idosos e terem maior disponibilidade de tempo e vínculo com a unidade, conseguiram se engajar em mais atividades de promoção e prevenção. Observa-se que a unidade de saúde e os grupos atuam como fatores protetores para essa população, favorecendo o cuidado e as relações socias. No entanto, percebe-se que fatores associados ao gênero ainda dificultam um melhor cuidado de saúde por parte de homens.

\section{Abstract}

Objective: to understand the perceptions of elderly men about the following themes: "Health", "Family Health Unit" and "Groups of Health Approaches". Methods: exploratory and descriptive survey with a qualitative approach, using a convenience sample. Participants were selected from a list of elderly men who used the health unit. A semi-structured interview was designed for data collection. The data were analyzed based on a thematic analysis orientation. Results: eleven men were interviewed. They showed a wide conception of health, considering biopsychosocial factors in their descriptions, as well as a good relationship with the Family Health Unit, where they go for medical appointments and to join health prevention and promotion groups. The participants reported that they did not undergo as many preventive activities as women. They evaluated Groups of Health Approaches as beneficial, with positive implications for health and for life. However some participants have group models from other contexts, especially from the work setting, which do not match the models recommended for Groups of Health Approaches. Conclusion: as the participants are elderly and have more available time and a greater relationship with the unit, they are able to engage in more activities of promotion and prevention at the Family Health Unit. This study also showed that the health unit and the groups act as protective factors for this population; elderly men favor receiving care and engaging in social relations. However, factors associated with gender still hinder a better health care for men.
Palavras-chave: Saúde do Homem Saúde do Idoso Atenção Primária à Saúde Promoção da Saúde

\section{Keywords:}

Men's Health Health of the Elderly Primary Health Care Health Promotion
Fonte de financiamento: declaram não haver. Parecer CEP: CSE/FMRP-USP Of $\mathrm{n}^{\circ}$ 056/11 de 16/03/2011.

Conflitos de interesse: declaram não haver. Recebido em: 04/09/2013. Aprovado em: 13/09/2014. 
Resumen

Objetivo: conocer la percepción de los hombres ancianos sobre los temas: "Salud", "Servicios de salud de la familia" y "Grupos de la Salud". Método: estudio exploratorio-descriptivo, con un enfoque cualitativo y muestra de conveniencia. Para la selección de los participantes se realizó una lista de hombres ancianos utilizando de servicios de salud de la unidad. Para la recolección de los datos se realizaron entrevistas semi-estructuradas y los datos fueron analizados según un análisis cualitativo. Resultados: participaron en el estudio 11 hombres ancianos; se observó que tienen un concepto amplio de la salud, abordando los factores biopsicosociales en sus descripciones. Con respecto a los servicios de salud de la familia, tienen un buen vínculo con la unidad, asistiendo a consultas y participando en grupos de promoción y prevención. Los participantes afirman tener un cuidado de la salud diferente de las mujeres, porque ellas realizan actividades de prevención. Sin embargo consideran que los grupos de salud tienen efectos positivos en ellos. Algunos tienen modelos de grupos de otros contextos, principalmente del trabajo, que no corresponden con el modelo de grupo de salud. Conclusión: los participantes al ser ancianos, tener más tiempo disponible y un vínculo cercano con la unidad, son capaces de participar en más actividades de promoción y prevención. También se observó que la unidad y los grupos actúan como factores de protección para esta población. Se advierte que los factores asociados con el género todavía obstaculizan un mejor cuidado de la salud de los hombres.

\section{Introdução}

O Sistema Único de Saúde (SUS) caracteriza a Atenção Primária à Saúde (APS) como um conjunto de ações de saúde, no âmbito individual e coletivo, com o objetivo de desenvolver uma atenção integral que impacte na situação de saúde e autonomia das pessoas e nos determinantes e condicionantes de saúde das coletividades. ${ }^{1}$

No Brasil, a Estratégia Saúde da Família (ESF) foi criada para reorientar o modelo assistencial da APS, por meio da implantação de equipes multiprofissionais em Unidades Básicas de Saúde, atuando com a lógica de território e população adstrita. ${ }^{2}$ A ESF elabora açóes que priorizam o cuidado ampliado de saúde dos usuários, ${ }^{3}$ mas percebe-se um distanciamento do homem no cuidado da sua saúde, devido à desvalorização dos homens pelos serviços e à dificuldade da equipe de acolher as necessidades dessa população. ${ }^{4}$

Ao analisar o tema "homens e saúde" deve-se considerar o caráter social do adoecimento e a perspectiva de gênero como forma particular da relação saúde-sociedade, $, 5,6,8$ em que gênero significa a maneira como as pessoas devem agir, pensar e sentir, para serem consideradas homens ou mulheres, sendo esses modelos transmitidos por meio da educação, meios de comunicação e convivência. ${ }^{9} 10$.

Dados nacionais indicam que, em cada três mortes de pessoas adultas, duas são de homens, sendo as principais causas de morte: doenças do aparelho circulatório, neoplasias e causas externas. ${ }^{2}$ Os homens, em média, vivem sete anos a menos do que as mulheres; possuem também maior incidência de doenças do coração, câncer, diabetes, hipercolesterolemia e hipertensão. ${ }^{2,11}$ A não adesão às medidas de saúde integral por parte dos homens leva ao aumento da incidência de doenças e de mortalidade. ${ }^{2}$

As diferenças entre os gêneros em termos de morbidade, mortalidade e expectativa de vida podem ser explicadas a partir de cinco fatores: (1) especificidades biológico-genéticas; (2) desigualdades sociais e étnicas; (3) expectativas sociais; (4) busca e uso de serviços de saúde; e (5) cuidados de profissionais de saúde voltados para homens. ${ }^{12}$ Observa-se que a maior taxa de mortalidade masculina não pode ser restrita ao sexo, devendo ser atribuída a fatores sociais e comportamentais. ${ }^{7}$

Ao buscar compreender os motivos da pouca procura de homens pelos serviços de saúde foram identificadas questôes relativas ao imaginário cultural sobre o que é ser homem; o medo de descobrirem que estáo doentes e a vergonha em expor o seu corpo. Outra questão é relativa ao mercado de trabalho, pela inexistência de garantias de que o acesso e a frequência dos homens aos serviços de saúde não os prejudicará em seus empregos. Além disso, as campanhas de saúde pública e os serviços de saúde não privilegiam esse segmento populacional, sendo pouco aptos a absorver as demandas masculinas. ${ }^{13}$

Quando se analisa a produção de conhecimento de saúde pública sobre "homem e saúde", três temáticas principais são apresentadas: sexualidade, reprodução e poder, o que demonstra a necessidade de ampliar os temas em pesquisa e aprofundar as relaçóes entre masculinidade e saúde. ${ }^{7}$ Desse modo é necessário compreender como essa população percebe os seus cuidados de saúde, para que intervençóes adequadas sejam propostas.

A fim de contribuir para o desenvolvimento de projetos e intervençôes em saúde pública, especialmente na APS, esta pesquisa teve como objetivo compreender a percepção de homens idosos acerca dos temas: "Saúde", "Unidade de Saúde da Família" e "Grupos em Saúde". 


\section{Método}

Trata-se de um estudo exploratório-descritivo, de abordagem qualitativa, com uma amostra de conveniência, desenvolvido em uma Unidade de Saúde da Família (USF). Os dados foram coletados entre agosto de 2011 e maio de 2012, em uma cidade localizada no interior do estado de Sáo Paulo. A USF foi implantada em 1999 e está inserida na proposta da Estratégia Sáude da Família (ESF). Além da equipe mínima, a USF também conta com a presença do auxiliar administrativo, auxiliar de serviços gerais, residentes médicos e multiprofissionais. Possui 2.384 usuários cadastrados, sendo $10 \%$ deles homens com mais de 60 anos. Nessa unidade acontecem semanalmente grupos de promoção de saúde, aos quais os participantes são convidados por meio de visitas de agentes comunitários de saúde (ACS), indicação da equipe e por cartazes presentes na unidade ou em outros locais de acesso da população. Os grupos desenvolvidos na unidade durante esse estudo foram de: Reeducação alimentar, Vivência, Homens, Adolescentes, Cuidadores, Memória, Hipertensão, Diabetes e Educação em Saúde.

Os participantes desse estudo foram homens com idade igual ou superior a 60 anos, usuários regularmente cadastrados na USF, que utilizavam os serviços da unidade, entre os anos de 2011 e 2012. Dos idosos cadastrados na USF foram excluídos nove participantes que possuíam alguma deficiência mental/cognitiva/fisica que impossibilitasse a realização das entrevistas e os homens que possuiam convênio médico, que não realizavam seu seguimento de saúde na USF, correspondendo a 71 sujeitos.

Excluindo esses participantes, foi elaborada uma lista pela equipe, em que constavam nomes dos homens idosos da área de cobertura da USF que participavam da rotina da unidade, por meio de consultas, grupos e visitas das ACS.

A escolha por essa população justifica-se pelo interesse em conhecer melhor os cuidados de saúde de homens idosos e por sua presença frequente na rotina da unidade.

Foi utilizada a ferramenta da saturação dos dados, não incluindo novos sujeitos quando os dados obtidos, na percepção dos pesquisadores, não apresentaram novos conteúdos. ${ }^{14}$ Por se tratar de uma amostra de conveniência e pelos participantes apresentaram um baixo repertório verbal, acredita-se que isso possa ter favorecido uma saturação com 11 entrevistas.

Para a coleta de dados adotou-se uma entrevista semiestruturada, elaborada pelos pesquisadores. As questóes foram dividas em quatro tópicos, visando identificar: dados sociodemográficos; percepção sobre saúde; relação com a USF; e concepção de Grupos em Saúde. As entrevistas duraram cerca de 30 minutos e foram gravadas e transcritas na íntegra. Consultaram-se os prontuários para completar dados de caracterização.

Os dados qualitativos foram analisados por meio da Análise de Conteúdo Temática. ${ }^{15}$ Essa análise ocorre mediante a exploração das unidades temáticas que compõem um discurso(comunicação), em que a presença/frequência dessas unidades denotam a importância e os modelos de comportamento existentes no discurso do individuo.

A técnica divide-se em: pré-análise, exploração do material, tratamento dos resultados e interpretação. ${ }^{15}$ A pré-análise consistiu em leituras consecutivas, com agrupamento dos temas pela semelhança, para que assim surgissem categorias. A exploração do material consistiu em recortar do texto as unidades de registros e palavras, buscando agrupá-las nos temas estabelecidos na pré-análise. Em seguida, escolheu-se como regra de contagem a frequência de palavras relacionada aos temas, que assim permitiram uma quantificação e sistematização dos dados em categorias, buscando alcançar os núcleos de compreensão do texto. $\mathrm{Na}$ terceira etapa foi realizada a análise e interpretação dos dados obtidos, em que inferências e interpretaçôes foram propostas em torno das dimensôes sugeridas pela leitura do material e considerando dados da literatura. Abaixo segue o Quadro 1 que apresenta um exemplo dessa análise.

Quadro 1. Demonstração da análise de conteúdo temática.

\begin{tabular}{cl}
\hline Etapas da análise de conteúdo temática & \multicolumn{1}{c}{ Descrição da analise de conteúdo temática e exemplo } \\
\hline Pré-análise & - Leituras consecutivas das verbalizações \\
& - Contato exaustivo com o material \\
& - Exemplo de verbalização - "Saúde é a melhor coisa que existe tendo saúde tem tudo." \\
& - Recortes do texto em unidades temáticas \\
& - Escolhem-se as categorias \\
& - Categoria: 0 que significa saúde \\
& - Subcategoria: Tudo - "(...) tendo saúde tem tudo" \\
& - Inferências e interpretações previstas no quadro teórico do material \\
& - Infere-se que essas descrições de saúde estão associadas à manutenção de atividades e de uma vida independente \\
& pelos participantes, condição de possibilidade para exercer suas atividades.
\end{tabular}


Esse estudo foi aprovado pelo Comitê de Ética em Pesquisa do Centro de Saúde Escola da Faculdade de Medicina de Ribeirão Preto da Universidade de Sáo Paulo sob o Ofício nº . 056/11 de 16/03/2011. Os usuários participaram da pesquisa mediante manifestação de interesse e após assinatura do Termo de Consentimento Livre e Esclarecido.

\section{Resultados e Discussão}

\section{Dados sociodemográficos}

Participaram desse estudo 11 homens idosos, que apresentaram uma média etária de 76,1 anos. A maioria estava aposentada, possuía baixa renda, residia com suas esposas/companheiras e possuía filhos e netos, como pode ser observado na Tabela 1.

Tabela 1. Caracterização sociodemográfica dos participantes $(n=11)$.

\begin{tabular}{ccc}
\hline Variável & Descrição & Participantes \\
\hline \multirow{2}{*}{ Estado civil } & Casado & 6 \\
& Viúvo & 5 \\
Idade & $67-70$ & 3 \\
& $70-80$ & 4 \\
Atividade profissional & $81-86$ & 4 \\
Renda média mensal (salário & Sim & 1 \\
mínimo) & Não (aposentado) & 10 \\
Composição familiar & $1-2$ & 8 \\
& $3-4$ & 3 \\
Filhos & Esposa & 6 \\
& Outros familiares & 4 \\
Netos & Sozinho & 1 \\
& Sim & 10 \\
\hline & Não & 1 \\
\hline
\end{tabular}

\section{Percepção sobre saúde}

$\mathrm{Na}$ Tabela 2 estão apresentados os significados de saúde para os participantes.

Tabela 2. Frequência das subcategorias sobre "0 que significa Saúde" para os participantes (n=11).

\begin{tabular}{|c|c|}
\hline Sub categorias & Frequência \\
\hline Liberdade & 23 \\
\hline Tudo & 22 \\
\hline Bem estar & 9 \\
\hline Ausência de problemas ou doenças & 6 \\
\hline Medicação & 5 \\
\hline Rotina & 4 \\
\hline Mudar hábitos & 4 \\
\hline Atividade física & 3 \\
\hline Alimentação adequada & 2 \\
\hline Privilégio & 2 \\
\hline Trazer exames e sair satisfeito & 1 \\
\hline Cultura & 1 \\
\hline Algo que precisa ser melhor cuidado pelos governantes & 1 \\
\hline
\end{tabular}


Observa-se nas falas a construção de um conceito de saúde ampliado, abordando aspectos biopsicosociais, não restringindo saúde à ausência de doença. As subcategorias com maior frequência foram Liberdade e Tudo, em que os participantes descrevem Liberdade como condição de possibilidade e ausência de restriçôes: "você pode andar, caminhar, passear" (P2); "eu acho que saúde é a gente viver bem(...) comendo bem, dormindo bem, andando bem, trabalhando bem" (P6). Em Tudo, a saúde foi descrita como algo imprescindível e prioritário para a vida: "tudo que tem de bom, o importante é a saúde, né? Eu acho, meu modo de pensar" (P2). "Saúde é tudo no mundo, você não tendo saúde você não tem nada" (P7).

Infere-se que essas descriçôes de saúde estão associadas à manutenção de atividades e de uma vida independente pelos participantes. Os homens foram educados para um papel de provedor, para desempenharem como elementos ativos em suas realidades, devendo sempre estar saudáveis para exercerem suas funções sociais. Essa concepção também foi encontrada no estudo de Figueiredo e Schraiber, ${ }^{16}$ em que o trabalho está diretamente ligado à concepção do que é ser homem. Nesse contexto, em que a maior parte dos entrevistados está aposentada, a saúde não está relacionada ao trabalho, mas eles se deparam com limitaçôes causadas pelo envelhecimento e diminuição de sua capacidade funcional, sendo que a saúde possui uma função essencial para a sua independência. Assim, para ser homem de acordo com o que o imaginário cultural representa é preciso ter saúde. ${ }^{4}$

Quando questionados sobre o que poderiam fazer para cuidar melhor de sua saúde, as principais respostas foram: Hábitos saudáveis e Evitar exageros. Em Hábitos saudáveis estão os cuidados com alimentação e atividades físicas: "É não comer doce, não abusar de comida" (P8); "poder participar mais de ginásticas, essas coisas, eu gostaria" (P9). Na categoria Evitar exageros, estão falas sobre evitar práticas que comprometam a saúde: "Porque não pode exagerar, porque já tem aquelas instrução (...) porque se exagerar já viu" (P6); "eu náo faço nada além do normal de extravagância, nunca fiz, não bebo, não fumo, não tenho esses problemas" (P9).

Observa-se que as práticas estão ligadas a um conceito ampliado de saúde, corroborando os dados de Camargo et al, ${ }^{17}$ em estudo realizado com homens de 16 a 67 anos, que afirmaram que uma alimentação saudável e práticas de atividade física constituem cuidados importantes para a saúde. Isso reforça a concepção de que os homens estão buscando práticas de cuidado de saúde pautadas na promoção e prevenção.

\section{Relação dos usuários com a USF}

O tempo médio de utilização da USF pelos participantes foi de cinco anos, sendo os principais motivos para utilizá-la: ir às consultas e nos grupos em saúde. Outros motivos elencados foram: "medir a pressão arterial", "fazer exames", "prescrição de medicamentos", "eventos comemorativos" "participar do programa de hipertensão", "agendar consulta", "acompanhar a esposa", "atendimento eventual" e "orientaçôes".

Os motivos de frequentar a USF para medir pressão arterial, glicemia, agendar consultas e participar do programa de hipertensão estáo de acordo com dados da literatura, que referem a presença de homens idosos para o tratamento e prevenção de doenças crônicas. ${ }^{18,19}$ Esta presença foi facilitada principalmente depois da inserção de programas voltados para a prevenção dessas doenças, como HIPERDIA (Sistema Nacional de Cadastramento e Acompanhamento de Hipertensos/ Diabéticos, garantindo medicação e estratégias de saúde), em que os idosos contam com mais espaço para suas demandas, fato que potencializa o acesso dos homens aos serviços. ${ }^{18,19}$

A respeito da percepção dos participantes sobre a USF, observou-se predominantemente que eles a consideram como um local de atendimento e um Benefício.

A descrição da USF como um local de atendimento inclui falas de acolhimento e de relação com a equipe: "É uma unidade, que todo pessoal que vem aqui é bem atendido(...) nunca tive problema, sempre que vim aqui fui bem atendido, nunca tive preocupação com doutor ou com doutora."(P1); "Eu acho bom na unidade que as pessoas são todas educadas, é uma beleza. Chega lá é atendido mesmo. E nesses outros médicos não é assim não (...) ali não, vixe! Na hora marcada certinha aí já vai."(P10). 
Como a amostra foi selecionada a partir de participantes que possuíam maior contato com a equipe, é possível inferir que essa relação pode estar associada ao vínculo que possuem com esses profissionais, característica condizente com o modelo da ESF, em que a equipe participa do processo de saúde/doença de seus usuários e os acompanha longitudinalmente. ${ }^{20}$ Devido à dificuldade de acessar os homens para o seu cuidado, ressalta-se a importância de um bom vínculo serviço de saúde-usuário, comunicação adequada e humanização do atendimento, para que se estabeleça uma relação de confiança. ${ }^{16,21}$

A subcategoria Benefício contém verbalizaçóes sobre USF proporcionar melhorias no cuidado e de ser uma boa proposta para a população: "A unidade é um beneficio da saúde, pode ser? O que se precisar procura um médico" (P8); "Acho que foi uma ideia muito boa, muito bom mesmo!" (P3). Apesar dos dados de Figueiredo ${ }^{4}$ indicarem que homens buscam mais serviços de pronto-atendimento, os entrevistados referem a USF como um aliado no cuidado de sua saúde. Isso pode estar relacionado ao acolhimento da equipe às solicitaçóes e demandas dessa população. Assim, pode-se inferir que a APS, oferecendo resolubilidade à população, favoreceria a manutenção desta sob seus cuidados. ${ }^{1,22}$

Esse estudo também buscou compreender a percepção dos participantes sobre o cuidado da saúde a partir da perspectiva de gênero, como pode ser observado na Tabela 3.

Tabela 3. Frequência das subcategorias sobre as diferenças entre homens e mulheres no cuidado à saúde $(n=11)$.

\begin{tabular}{lc}
\hline \multicolumn{1}{c}{ Sub categorias } & Frequência \\
\hline Mulher realiza mais atividades preventivas & 15 \\
Homem não se importa com a saúde & 11 \\
Mais problemas de saúde ligados ao sexo feminino & 5 \\
Mulheres possuem mais atividades sociais & 4 \\
Homem tem medo & 4 \\
Homem não acredita que fica doente & 4 \\
Mulher se expõe a menos riscos & 2 \\
Homem é mais vaidoso & 1 \\
\hline
\end{tabular}

Observa-se que, na percepção dos participantes, existem diferenças entre os gêneros no que se refere ao cuidado à saúde. Exemplifica-se: "Minha mulher era assim. Ela falava 'vou na unidade ou no postinho'. Eu pagava também pra ela o convênio da policlínica,(...) Então ela consultava nos dois, no postinho e lá" (P10); "Eu vejo que os caras lá do PIC (Programa de Interaçáo com a Comunidade), acho que tem quatro homens lá só, e acho tem umas 60 mulher(...) Por aí você já vê que mulher cuidam mais do que os homens" (P2). Outro relato que exemplifica a diferença no cuidado: "Homem é meio relaxado(...) homem só vai ao médico quando tá doente mesmo, senão, não procura de jeito nenhum" (P2); "o homem parece não ligar para sua saúde" (P10).

Porém, essa característica de cuidado não é intrínseca à natureza masculina, sendo levantada como motivo a diferença de socialização masculina e feminina. ${ }^{10,13,23}$ As mulheres são incentivadas a cuidar de si, da família, enquanto o homem deve ser forte e viril, correspondendo ao modelo hegemônico de masculinidade. ${ }^{10,13,23}$ Isso pode ser observado na fala de um dos participantes: "Acho que mulher é mais delicada(...) além disso, elas têm mais, homem parece que não liga para saúde(...) Ah não sei, acho que é da natureza as mulheres cuidarem melhor, acho que da própria natureza(...) acho que elas têm a natureza de cuidar melhor, elas cuidam até da gente" (P10).

Dentro de uma perspectiva cultural, nota-se que o homem sempre desempenhou um papel de provedor e trabalhador, sendo valorizado a ser forte para desempenhar suas funçôes sociais, não sendo incentivado para as práticas preventivas, procurando atendimento apenas diante de quadros já instalados. ${ }^{21,24,25,26}$ No entanto, devem-se considerar, como aponta Baker, ${ }^{23}$ as dificuldades de se criarem políticas públicas que compreendem os homens como seres de gênero, bem como sua diversidade de identidades. ${ }^{23}$ No Brasil, a atenção à saúde direcionada aos homens só teve destaque vinte anos mais tarde do que as políticas referentes às mulheres e se processou por meio de uma decisão política, ao contrário das políticas das mulheres, decorrentes de um processo histórico de lutas de direito. ${ }^{5,26}$ Isso demonstra, ainda, um processo de construção na busca por uma saúde integral no cuidado do homem, que precisa empoderar esses homens sobre o seu cuidado. ${ }^{23}$ 


\section{Grupos em Saúde}

Investigou-se o conhecimento dos participantes sobre os grupos realizados na USF, bem como seus benefícios. Todos os participantes relataram conhecer os grupos realizados, sendo que 10 participantes referiram ter participado de alguns deles e um participante considerou negativo participar de grupos.

Os participantes consideraram os grupos como um local de Aquisição/troca de informaçóes, um espaço de conversa entre os participantes e profissionais: "é bom estar por dentro da saúde, o que é bom pra saúde, o que não é" (P2); "a pessoa sendo orientada, ele vai atrás daquilo, né? Vai saber, vai procurar!(...) É bom porque elas ensina a gente, uns fala uma coisa, outros fala outra, outros fala outra e aquilo vai deixando a pessoa bem encaminhada, pra procurar saúde!" (P6). Também descrevem o grupo como um local que Incentiva o auto-cuidado, onde participantes, diante da fala dos colegas, reavaliam sua saúde: "às vezes eu não tenho nada, mas às vezes uma outra pessoa tem um problema meio diferente 'pô, será que eu tenho isso dai?' mas aí eu faço exame e náo tem" (P1).

O grupo foi considerado como um espaço de trocas, aprendizado e de cuidado com sua saúde, em que são abordados temas de interesse e reflexão sobre saúde e bem-estar. Os grupos também favorecem a convivência social, o que adquire maior importância quando o homem está aposentado. ${ }^{27}$ Diante da diminuição da sua participação social, esses homens podem adoecer ou buscar atividades relacionadas ao consumo de bebidas alcoólicas e jogos de azar. ${ }^{28,29,30,31}$ A partir disso, ressalta-se a necessidade de mais espaços grupais para as demandas masculinas dentro dos serviços de saúde, para que homens empoderem-se do cuidado de saúde. Isso corrobora os estudos de Gomes et al ${ }^{21}$ que refere a necessidade de homens terem mais espaços de trocas em grupos dentro dos serviços de APS.

Outra concepção apresentada por um dos participantes foi do grupo ser um local que apresenta uma relação verticalizada, em que há uma relação de poder pelos profissionais, em que estes são os detentores do conhecimento: "Vai ter aquela conversa (...). Aquela conversa que a gente já sabe o que vai falar, (...) Chega lá tem uma psicóloga, uma doutora, cada um fala um pouco, aquela rotina (...) eu acho que a unidade ai também deve ser igual, porque quem vai falar são os médicos, não é isso? Quem vai falar vai ser o psicólogo, vai ser a doutora disso, doutora daquilo, né? A gente fica ouvindo, né?"(P11).

Apesar de esse participante não ter frequentado um grupo na USF, percebe-se que durante a sua vida ele teve contato com espaços coletivos, principalmente relacionados ao contexto de trabalho: "Quando era comerciante, eu participava da conversa lá na ACI (Associação do Comércio e Indústria), primeiro falava tudo os 'Cobras', os grandes comerciantes, industriais. A gente sentava bem lá pra atrás, acabava a reunião, vinha embora(...)Eu conhecia diversas pessoas que iam lá. Mas a gente sentava bem lá pra atrás, dificilmente chamava a gente, primeiro falava os mais grosso, depois o restante...Só ouvia, ficava lá, vamos dizer o que? Mas só que lá no livro da ata tinha que assinar, né?" (P11).

Apesar de a Promoção de Saúde considerar que melhores condiçóes de vida e saúde só serão atingidas por meio de participação popular, pressupondo espaços de grupos, definidos por uma relação horizontal, nota-se que o processo cultural atual cria resistências para essas mudanças, pois vivemos em uma sociedade verticalizada, principalmente as instituiçóes e organizaçóes empresariais. ${ }^{32}$ Dessa forma, por meio do discurso desse participante observa-se uma crença social, que pode contribuir para o afastamento de homens de grupos em saúde, pois esses sempre estiveram inseridos no mercado de trabalho e foram expostos a grupos de trabalho hierarquizados, em que apenas os detentores de poder/saber poderiam ter voz. Apesar dos avanços na saúde, por meio de políticas públicas, como a criação do SUS, pelas Leis 8.080/90 33 e 8.142/90, ${ }^{34}$ e a Política Nacional de Humanização (PNH), ${ }^{35}$ que propóem o controle social e a responsabilidade compartilhada médico-usuário, ainda está presente culturalmente uma concepçáo de submissão. Assim, se faz necessário construir um novo paradigma que poderia contribuir para uma melhor efetivação da política de promoção de saúde, bem como maior inserção do homem em grupos.

O Ministério da Saúde (MS) instituiu a Política Nacional de Atenção Integral à Saúde do Homem (PNAISH), ${ }^{36}$ fruto de decisōes políticas, não contando com a participação masculina em sua construção ${ }^{23,37}$. Apesar dos avanços que essa política trouxe para a saúde do homem, ela possui limitaçóes, tais como a não inclusão do idoso. ${ }^{38}$ Apesar do MS ter criado a Política Nacional do idoso ${ }^{39}$ que favorece um olhar ampliado sobre essa população, considera-se que os homens possuem necessidades de saúde relacionadas ao seu papel de gênero, as quais seriam mais bem abordadas diante dessa perspectiva. A partir do diálogo entre as políticas públicas é que se produzirá um cuidado integral à saúde do homem.

Para a implementação da PNAISH na APS, destaca-se a necessidade de reconhecer as demandas de saúde do homem; trabalhar com planejamento estatal para viabilizar um plano de ação consistente; investir na capacitação de gestores e profissionais de assistência para que reconheçam as necessidades de saúde dos homens como multideterminadas; e promover a participação social na construção e avaliação das ações políticas. ${ }^{25}$ 


\section{Conclusão}

Este estudo forneceu informaçóes sobre o que pensam os usuários homens idosos de uma USF sobre temas relevantes em saúde, incluindo suas opiniôes sobre o serviço prestado pela USF e os Grupos em Saúde. Os participantes, por serem idosos e terem maior disponibilidade de tempo e vínculo com a unidade, engajaram-se mais nas atividades de promoção e prevenção. Observa-se também que a unidade de saúde e os grupos atuam como fatores protetivos para essa população, pois favorecem o cuidado e as relaçóes sociais. No entanto, percebe-se que as questôes relacionadas ao gênero ainda dificultam o cuidado de saúde por parte dos homens. Assim, o estudo aponta para a necessidade de melhorar a relação entre as políticas públicas e a assistência integral à saúde do homem. Além disso, sugere que conhecer a percepção de homens idosos sobre o cuidado de sua saúde é fundamental para que se busque uma atenção integral condizente com as necessidades dessa população.

\section{Referências}

1. Ministério da Saúde (BR). Política Nacional de Atenção Básica. Brasília: Ministério da Saúde; 2012. (Série E. Legislação em Saúde).

2. Ministério da Saúde (BR). Sistema Único de Saúde. Apresentação [Internet]. Brasília; c2014 [acesso em 2011 Nov 22]. Disponível em: http://portal.saude.gov.br/portal/saude/default.cfm.

3. Freitas MLA, Mandú ENT. Promoção da saúde na Estratégia Saúde da Família: análise de políticas de saúde brasileiras. Acta Paul Enferm [Internet]. 2010 [acesso em 2012 Nov 1];23(2):200-205. Disponível em: http://dx.doi.org/10.1590/S0103-21002010000200008.

4. Figueiredo WS. Assistência à saúde dos homens: um desafio para os serviços de atenção primária. Ciênc Saúde Coletiva [Internet]. 2005 [acesso em 2011 Oct 05];10(1):105-109. Disponível em: http://dx.doi.org/10.1590/S1413-81232005000100017.

5. Schraiber LB, Gomes R, Couto MT. Homens e saúde na pauta da Saúde Coletiva. Ciênc Saúde Coletiva [Internet]. 2005 [acesso em 2011 Jul 13];10(1):7-17. Disponível em: http://dx.doi.org/10.1590/S1413-81232005000100002.

6. Gomes, R. Sexualidade masculina e saúde do homem: proposta para uma discussão. Ciênc Saúde Coletiva [Internet]. 2003 [acesso em 2011 Nov 10];8(3):825-9. Disponível em: http://dx.doi.org/10.1590/S1413-81232003000300017.

7. Laurenti R, Jorge MHPM, Gotlieb SLD. Perfil epidemiológico da morbi-mortalidade masculina. Ciênc Saúde Coletiva [Internet]. 2005 [acesso em 2011 Oct 06];10(1):35-46. Disponível em: http://dx.doi.org/10.1590/S1413-81232005000100010.

8. Gomes R, Nascimento EF. A produção do conhecimento da saúde pública sobre a relação homem-saúde: uma revisão bibliográfica. Cad Saúde Pública [Internet]. 2006 [acesso em 2012 Nov 15];22(5):901-911. Disponível em: http://dx.doi.org/10.1590/S0102-311X2006000500003.

9. Keijzer B, Ayala G, Dorantes OA, Rosas EMR, Sánchez-Mejorada J, Barranca SM, Salud y gênero. Razões e emoções. São Paulo: 3Laranjas Comunicação; 2001 [acesso em 2013 Jan 15]. (Série Trabalhando com Homens Jovens, caderno 4). Disponível em: http://www.promundo.org.br/wp-content/uploads/2010/04/RazoeseEmocoes1.pdf.

10. Gomes R. A saúde do homem em foco. São Paulo: Editora UNESP; 2010.

11. Brasil. Rede Interagencial de informações para a saúde (RIPSA). Indicadores e Dados Básicos 2006 - Brasil. Brasília: Ministério da Saúde; 2010 [acesso em 2013 May 14]. Disponível em: http://tabnet.datasus.gov.br/cgi/idb2006/matriz.htm.

12. Mckinlay E. Men and Health: a literature review [Internet] Wellington: Wellington School of Medicine as Health Science, Otago University; 2005 [acesso em 2012 Nov 30]. Disponível em: http://nhc.health.govt.nz/system/files/documents/publications/mens-health-literature-review.pdf.

13. Gomes R, Nascimento EF, Araujo FC. Por que os homens buscam menos os serviços de saúde do que as mulheres? As explicações de homens com baixa escolaridade e homens com ensino superior. Cad. Saúde Pública [Internet]. 2007 [acesso em 2012 Nov 17];23(3):565-574. Disponível em: http://dx.doi.org/10.1590/S0102-311X2007000300015.

14. Fontanella BJ B, Ricas J, Turato ER. Amostragem por saturação em pesquisas qualitativas em saúde: contribuições teóricas. Cad Saúde Pública [Internet]. 2008 [acesso em 2014 Jul 25];24(1):17-27. Disponível em: http://dx.doi.org/10.1590/S0102-311X2008000100003.

15. Minayo MCS. O desafio do conhecimento: pesquisa qualitativa em saúde. São Paulo: Hucitec/Abrasco; 1994.

16. Figueiredo WS, Schraiber LE. Concepções de gênero de homens usuários e profissionais de saúde de serviços de atenção primária e os possíveis impactos na saúde da população masculina, São Paulo, Brasil. Ciênc Saúde Coletiva [Internet]. 2011;16(1):935-944. Disponível em: http://dx.doi.org/10.1590/S1413-81232011000700025.

17. Camargo BV, Campos PHF, Torres TL, Stuhler GD, Matão MEL. Representações sociais de saúde e cuidado: um estudo multicêntrico sobre vulnerabilidade masculina. Temas Psicol [Internet]. 2011 [acesso em 2013 Apr 26];19(1):179-192. Disponível em: http://pepsic.bvsalud.org/scielo.php?script=sci_arttext\&pid=S1413-389X2011000100014\&lng=pt.

18. Knauth DR, Couto MT, Figueiredo WS. A visão dos profissionais sobre a presença e as demandas dos homens nos serviços de saúde: perspectivas para a análise da implantação da Política Nacional de Atenção Integral à Saúde do Homem. Ciênc Saúde Coletiva.

2012;17(10):2617-2626. Disponível em: http://dx.doi.org/10.1590/S1413-81232012001000011. 
19. Couto MT, Pinheiro TF, Valença OA, Machin R, Silva GSN, Gomes R, et al. O homem na atenção primária à saúde: discutindo (in)visibilidade a partir da perspectiva de gênero. Interface (Botucatu) [Internet]. 2010 [acesso em 2012 Oct 05];14(33):257-270. Disponível em: http://dx.doi.org/10.1590/S1414-32832010000200003.

20. Ministério da Saúde (BR), Secretaria de Atenção à Saúde, Política Nacional de Humanização. Atenção Básica. Brasília: Ministério da Saúde; 2010 [acesso em 2014 Jan 29]. (Série B. Textos Básicos de Saúde) (Cadernos HumanizaSUS, vol. 2). Disponível em: http://bvsms.saude.gov.br/bvs/publicacoes/cadernos_humanizasus_atencao_basica.pdf.

21. Gomes R, Moreira MCN, Nascimento EF, Rebello LEFS, Couto MT, Schraiber LB. Os homens não vêm! Ausência e/ou invisibilidade masculina na atenção primária. Ciênc Saúde Coletiva [Internet]. 2011 [acesso em 2012 Sep 20];16(1):983-992. Disponível em: http://dx.doi.org/10.1590/S1413-81232011000700030.

22. Nunes AA, Caccia-Bava MCGG, Bistafa MJ, Pereira LCR, Watanabe MC, Santos V, et al. Resolubilidade da estratégia saúde da família e unidades básicas de saúde tradicionais: contribuições do Pet-Saúde. Rev Bras Educ Med [Internet]. 2012 [acesso em 2013 Nov 16];36(1):27-32. Disponível em: http://dx.doi.org/10.1590/S0100-55022012000200004.

23. Baker G. Trabalho não é tudo, mas é quase tudo: homens, desemprego e justiça social em Políticas Públicas. In: Medrado B, Lyra J, Azevedo M, Brasilino J, editors. Homens e masculinidades: práticas de intimidade e políticas públicas. Recife: Instituto PAPAl; 2010. p. 125-138.

24. Pinheiro RS, Viacava F, Travassos C, Brito AS. Gênero, morbidade, acesso e utilização de serviços de saúde no Brasil. Ciênc Saúde Coletiva [Internet]. 2002 [acesso em 2013 Jan];7(4):687-707. Disponível em: http://dx.doi.org/10.1590/S1413-81232002000400007.

25. Couto MT, Gomes R. Homens, saúde e políticas públicas: a equidade de gênero em questão. Ciênc Saúde Coletiva [Internet]. 2012 [acesso em 2013 Nov 27];17(10):2569-2578. Disponível em: http://dx.doi.org/10.1590/S1413-81232012001000002.

26. Oliveira GR, Trilico MLC, Paro FS, Kijimura MY, Pirolo SM. A integralidade do cuidado na saúde do homem: um enfoque na qualidade de vida. Rev Bras Med Fam Comunidade [Internet]. 2013 [acesso em 2013 Nov 13];8(28):208-212. Disponível em: http://dx.doi.org/10.5712/rbmfc8(28)676.

27. Vecchia RD, Ruiz T, Bocchi SCM, Corrente JE. Qualidade de vida na terceira idade: um conceito subjetivo. Rev Bras Epidemiol [Internet]. 2005 [acesso em 2014 Jan 29];8(3):246-252. Disponível em: http://dx.doi.org/10.1590/S1415-790X2005000300006.

28. Duarte CV, Melo-Silva LL. Expectativas diante da aposentadoria: um estudo de acompanhamento em momento de transição. Rev Bras Orientac Prof [Internet]. 2009 [acesso em 2014 Jan 29];10(1):45-54. Disponível em: http://pepsic.bvsalud.org/scielo.php?script=sci_arttext\&pid=S1679-33902009000100007\&lng=pt\&tlng=pt.

29. Harris E, Harris MF. Reducing the impact of unemployment on health: revisiting the agenda for primary health care. Med J Aust [Internet]. 2009 [acesso em 2013 May 14];191(2):119-122. Disponível em: http://mja.com.au/public/issues/191_02_200709/har10340_fm.html.

30. Giatti L, Barreto SM. Situação do indivíduo no mercado de trabalho e iniqüidade em saúde no Brasil. Rev Saúde Pública [Internet]. 2006 [acesso em 2013 Jan 10];40(1):99-106. Disponível em: http://dx.doi.org/10.1590/S0034-89102006000100016.

31. Coutinho RX, Acosta MAF. Ambientes Masculinos da terceira idade. Ciênc Saúde Coletiva [Internet]. 2009 [acesso em 2013 Jan 13];14(4):11111118. Disponível em: http://dx.doi.org/10.1590/S1413-81232009000400017.

32. Horta NC, Sena RR, Silva MEO, Tavares TS, Caldeira IM. A prática de grupos como ação de promoção da saúde na estratégia saúde da família. Rev APS. 2009;12(3):293-301.

33. Brasil. Lei n. 8.080, de 19 de setembro de 1990. Dispõe sobre as condições para a promoção, proteção e recuperação da saúde, a organização e o funcionamento dos serviços correspondentes e dá outras providências. Diário Oficial da União. 1990 Sep 20 ; Seção 1.

34. Brasil. Lei n. 8.142, de 28 de dezembro de 1990. Dispõe sobre a participação da comunidade na gestão do Sistema Único de Saúde (SUS\} e sobre as transferências intergovernamentais de recursos financeiros na área da saúde e dá outras providências. Diário Oficial da União. 1990 Dec 31; Seção 1.

35. Ministério da Saúde (BR), Secretaria-Executiva, Núcleo Técnico da Política Nacional de Humanização. Humaniza SUS. Política Nacional de Humanização: a humanização como eixo norteador das práticas de atenção e gestão em todas as instâncias do SUS. Brasília: Ministério da Saúde; 2004. (Série B. Textos Básicos de Saúde).

36. Ministério da Saúde (BR), Secretário de Atenção à Saúde. Política nacional de atenção à saúde do homem: princípios e diretrizes. Brasília: Ministério da Saúde; 2008.

37. Medrado B, Lyra J, Azevedo. ‘Eu Não Sou Só Próstata, Eu Sou um Homem!' Por uma política pública de saúde transformadora da ordem de gênero. In: Gomes R, editor. Saúde do Homem em debate. Rio de Janeiro: Editora Fiocruz; 2011. p. 39-74.

38. Ciênc Saúde Coletiva. 2005 [acesso em 2013 Jan 13];10(1). Disponível em: http://www.scielo.br/scielo.php?script=sci_issuetoc\&pid=1413$812320050001 \& \operatorname{lng}=$ pt\&nrm=iso

39. Ministério da Saúde (BR). Portaria n 2.528 de 19 de outubro de 2006. Aprova a Política Nacional de Saúde da Pessoa Idosa. Disponível em: http://dtr2001.saude.gov.br/sas/PORTARIAS/Port2006/GM/GM-2528.htm 
Anexo 1. Roteiro de entrevista.

Data:

Entrevistador:

\section{Dados Sociodemográficos}

1)Nome:

2) Data de Nascimento:

I________

Idade:

anos

3) Estado Civil

a) Casado

b) Solteiro

c) Divorciado

d) Viúvo

e) Mora junto

4) Profissão/ocupação:

5) Você possui alguma atividade remunerada?
( ) Sim
( ) Não

Renda (Salário mínimo - R \$

6) Quantas pessoas dependem dessa renda?

7) Somando os salários de todos que trabalham na sua casa, a renda familiar é:

a) Abaixo de um salário mínimo

b) Entre 1 a 2 salários mínimos

c) Entre 3 a 4 salários mínimos

d) Entre 5 a 6 salários mínimos

e) Acima de 6 salários mínimos 


\section{Composição familiar}

8.1) Possui filhos?

( ) Sim - Quantos:

( ) Não

8.2) Possui netos?

( ) Sim - Quantos:

( ) Não

8.3) Quem mora com o senhor? (Parentesco e idade)

\section{Saúde}

1) Para o senhor, o que é saúde?

2) Como o senhor avalia a sua saúde?
( ) Ótima
( ) Boa
( ) Regular
( ) Péssima

3) O senhor considera que possui alguma doença?

( ) Sim

( ) Nâo

Se sim, quais?

Quem disse que o senhor possui doença (Algum profissional? De onde? De que especialidade?)

4) Faz uso de medicamentos?
( ) Sim
( ) Não

Se sim, qual e para qual finalidade toma? 
Quem prescreveu o remédio (médico, farmacêutico)? Ou o senhor decidiu tomar por conta própria?

5) O que o senhor pensa que poderia fazer para melhorar ainda mais sua saúde?

6) Realiza atividades físicas?
( ) Sim
( ) Não

Se sim, quais atividades e com que frequência as realiza (por quanto tempo e quantos dias por semana)?

7) O senhor conhece alguma atividade oferecida pela comunidade? (Ex: Programa de Integração Comunitária - PIC, atividades em igrejas, atividades nos núcleos, Organizaçóes Não Governamentais - ONGs)

( ) Sim

( ) Não

Se sim, quais?

Participa de alguma dessas atividades que o senhor conhece?

8) Você acha que os homens cuidam de sua saúde da mesma maneira que as mulheres cuidam da saúde delas?

\section{Unidade Saúde da Família}

1) Para o senhor, o que é a Unidade Saúde da Família? 
2) Há quanto tempo o senhor utiliza os serviços da Unidade Saúde da Família?

3) Quando o senhor vai a Unidade Saúde da Família, o que você faz lá?

4) O senhor costuma ir a Unidade Saúde da Família apenas quando tem consulta agendada ou também vai em outras ocasiōes (eventual, grupos, outros eventos)?

\section{Grupos}

1) O senhor já ouviu falar de grupos que acontecem na Unidade Saúde da Família?

2) Já participou de algum grupo? Qual?

3) Você acha que participar de algum grupo pode trazer algum benefício? 